Author-produced version of the article published in Journal of Environmental Planning and Management, Volume 52, Issue 5, July 2009 , pages $613-630$

Original Publication available at http://www.informaworld.com ( Routledge Taylor \& Francis)

http://dx.doi.org/10.1080/09640560902958164

\title{
Threshold effect and coordination of agri-environmental efforts
}

Pierre Dupraz $^{a^{*}}$, Karine Latouche ${ }^{\mathrm{b}}$ and Nadine Turpin ${ }^{\mathrm{c}}$

${ }^{\mathrm{a} I N R A, ~ U M R ~ 1302, ~ S M A R T, ~} 35000$ Rennes, France

${ }^{\mathrm{b}}$ INRA, UR 1134, LERECO, 44000 Nantes, France

'CEMAGREF, UMR 1273 Métafort AgroParisTech-Cemagref-ENITA-INRA, 63000

AUBIERE, FRANCE

No senior authorship is involved

* Corresponding author: Pierre Dupraz, INRA-SMART, CS 61103, 35011 Rennes Cedex,

France. Tel : +33223485606, Fax :+33223485380, e-mail : pierre.dupraz@rennes.inra.fr 
Title:

Threshold effect and coordination of agri-environmental efforts 


\title{
Threshold effect and coordination of agri-environmental efforts
}

\begin{abstract}
This paper deals with policy mechanism designs for agri-environnemental schemes when the bio-physical processes are characterized by threshold effects. There is a threshold effect when specified farming practices must be applied on a minimal share of an area of interest to trigger perceptible changes of the state of the natural environment. Schemes result in a pure economic loss if the induced agro-environmental efforts are not sufficient. Different situations are considered including the lack of information on farmers' characteristics or actions, uncertainty on the relationship between farming practices and environmental quality, and combined difficulties of scheme design.
\end{abstract}

Keywords: threshold effect, agri-environmental policy

JEL: Q28, Q57 


\section{Threshold effect and coordination of agri-environmental efforts}

\section{Introduction}

When threshold effects characterise the processes involved in the environmental quality on a given area, the regulators need specific skills to ensure that the environmental effectiveness of the policy design. We deal with a simple case of threshold effect: no perceptible change in the environmental state occurs unless a specified farming practice is applied with a minimal intensity and on a minimal area in the zone of interest. The efficiency of agri-environmental schemes is particularly vulnerable to threshold effects because farmers' participation is voluntary and contractors may adjust their enrolled area in most cases. The analysis of the environmental performance of agri-environmental schemes, realised in the ITAES project in 9 case study regions, show that participation is the performance factor that most impedes scheme efficiency. In three regions, participation rate and geographical targeting are the two factors that limit environmental performance most (Finn et al., 2007). Although threshold effects are not always involved in analysed schemes, these results illustrate the importance of this issue.

Threshold effects on ecological discontinuities have been defined by Muradian (2001) as sudden modifications of a given system property, resulting from the soft and continuous variation of an independent variable. The examples for such discontinuities are numerous in the ecological literature: increase of the vulnerability to additional perturbations for ecosystems that have been previously submitted to strong anthropogenic pressure (Levin 1998), modifications in the equilibrium of temperate lakes (Weisner et al. 1997), colonisation by undesired species (Asner et Vitousek 2005), habitat fragmentation and disappearance of species (Kennedy et al. 2002), management of renewable resources.

The existence of discontinuities in the ecological processes that underline the renewing of natural resources like fishes, forests, soils, hunted animals or newly introduced species, induce 
strong nonlinearities that are largely addressed in management of renewable resources (Dasgupta et Maler 2003; Wirl 2004). The management of such resources, when thresholds occur, is characterised by the existence of multiple equilibriums, and thus the design of management policies needs to be dynamic (Maler 2000; Mitra et Roy 2006; Rondeau 2001; Toman et Withagen 2000).

In Europe, agri-environmental policies aim at preserving natural and semi-natural resources like biodiversity, rural landscapes, surface and groundwater quality, mostly using voluntary agreements (OCDE 2003) : a regulator proposes to a population of farmers to voluntarily adopt management practices that are supposed to be better than the current ones, against financial support for over costs. This regulator can base her policy on a large literature on thresholds effects, on their consequences upon the requested properties for accurate regulation policies, but generally this literature does not address the specific problem that this regulator faces. Because the available information is generally not precise enough for each regulated area, local regulators are often bounded to design policies without considering thresholds effects, which decreases strongly the efficiency of the regulation and leads to a waste of public fund: more and more empirical studies describe the adoption of good management practices, with important efforts from the population and sometimes with large public subsidies, with no noticeable modification of the environmental quality (Muradian, 2001).

The probability of wasting public funds is increased when asymmetric information occurs between the regulator and the farmers. Uptake mainly depends on the economic incentive offered to eligible farmers. However, the success of such schemes also depends on the individual characteristics of the eligible farms (Vanslembrouck et al., 2002), on the social context (Morris et Potter, 1995) on the different farm and extension networks (Bonnieux et al., 2001). When she designs a policy, the regulator cannot consider individual characteristics of all 
the eligible farms. These asymmetries of information create inefficiencies, that can however be reduced (Laffont et Martimort, 2002).

We focus on the paper on agri-environmental schemes that address two difficulties: threshold effects and asymmetries of information. Literature provides mechanism design in some situations. For threshold effects a two stage allocation of conservation funds has been proposed to optimally target conservation efforts: in the first stage, the allocation across the eligible sites ensures that thresholds are met in every selected site while within site fund allocation only needs to be based on a physical criterion of environmental effectiveness (Wu, 2004). An important issue related to threshold effects is the uncertainty with which they are associated. Perrings and Pearce (2004) provided a general framework to design the optimal mandatory policy dealing with certain and uncertain ecological thresholds. When asymmetries of information occur, and for non-point source pollutions only, optimally differentiated mechanisms ensure that each producer chooses the instruments (effort or practice) that have been designed for him (Wu et Babcock, 1996 ; Bontems et al., 2005).

Starting from an analysis of particular agri-environmental schemes and EU wide sample, this paper highlights the scattering of agri-environmental efforts that result from the different schemes designed last years. This analysis also depicts the main characteristics of the benefit functions for the regulators when they expect an improvement of the environment. Last, the analysis enables the elaboration of a typology for the agri-environmental situations; this typology relies on the different uncertainties occurring from hidden farmers' behavior or biophysical processes.

For each situation in this typology, we propose and discuss the possibility to design simple contracts. Simple standard contracts are considered regarding the high transaction costs involved in the management of differentiated contracts. The modelling suggests that the 
regulator can make of the direct utility that farmers derive from specific environmental goods they contribute to supply, and arouse cooperation behaviour. For example, when the regulator sends a signal, like the institution of a minimal rate of contracting intentions before signing any contract, this signal can easily consist in information that contributes to increase the probability of commitment by farmers that have a positive attitude towards the environment. Moreover, when the environmental objective matches a strong social demand, but is characterised by uncertain threshold effects, a perennial and progressive management of the scheme allows capitalising the local competences as the first implemented measures include the reduction of the uncertainties in their objectives.

In this paper, we finally analyse a concrete example that illustrates the existence of threshold effect. The practical possibility for a regulator to design a progressive scheme is described.

The paper is organised as follows: Section 2 describes the context of agri-environmental measures adoption with national or regional programmes. This description illustrates the phenomenon of scattering of committing farms. Section 3 designs a behaviour model for farmers who face agri-environmental measures and analyses the proprieties of such schemes when they are design in complete information situations. In the Section 4, this assumption of complete information is weakened: we examine here how the agri-environmental schemes are modified when the regulator cannot observe the farmers' willingness to accept. The Section 5 focuses, mostly through literature, the other combinations of uncertainties that a regulator may face. The last Section concludes.

\section{Voluntary adoption and scattering of agri-environmental efforts}

At the farm level, attempts to take into account scale and threshold effects may be limited by the Commission degressive rules, introduced and enforced with 1257/99 AESs, as a new component in the budget management. The average payment per hectare decreases according to 
the area under contract, the mix of area based measures being the same (punctual or linear elements/measures are not concerned by such rules). The payment calculation is done as follows:

Sum of the different measure committed areas, each committed area being multiplied by the corresponding payment per hectare(= theoretical aid amount);

$>$ this amount is then divided by the total enrolled area (= average amount/ha);

$>$ the actual payment is then calculated by intervals of committed area, with per hectare payment equalling $100 \%$ under 2 SMIs, $60 \%$ between 2 and 4 SMIs and 30\% above 4 SMIs. Defined in article L312-6 of the Rural Code, the SMI is presented as the minimum farm area from which a standard household is supposed to get enough income for a basic living. The value of the SMI is set at the NUTS 3 level according to farm types. Regularly revised, the SMI cannot, in any case, be less than $30 \%$ of the national SMI and is revised every 5 years.

Thus in the French case, the degressive rule can be in contradiction with some AES environmental objectives because it discourages large farm to enrol large areas. Scale and threshold are taken into account in very few French measures: the grassland premium must be applied on the whole farm, the payment for winter coverage or arable land depend on the share of eligible land which is enrolled.

Coordination between farms at a higher territorial level is usually not enforced. Contract applications and conclusions are considered by the administration on an individual basis. The territorial approach presented in section 4.3 remains an exceptional procedure. Yet a CNASEA report published in 1996 (CNASEA, 1996) dealing with the results of a French survey on 1183 farmers under contracts 2078/92 highlighted the willing of farmers to avoid dispersion in contracts signed. They insisted on the importance of reaching a minimum area under contract in a precise area. $51 \%$ of interviewees proposed to enhance efficiency of agro-environmental 
contracts through a minimum rate of adoption. $48 \%$ of interviewees also proposed that contracts should be applied on the whole farm instead of just a part of the farm. All this recommendations and farmers' advice were not taken into account in the French application of the regulation $1257 / 99$

The low rate of compliance is a real problem in France.

In Basse-Normandie it indeed appeared that some $40 \%$ of the farmers faced some difficulties to enforce the 1257/99 contracts (Eureval-C3E, 2003) - mainly its environmental part - mainly due to the framework planning and to the technical respect of some of the prescriptions.

Hence even in a ideal case of collective contracts signed only if the minimal targeted area is concerned, the provision of the environmental good can fail because the global effort of production (individual respect of contract commitments) is not effective.

The same holds in Brittany. The compliance controls lead nearly to the same results. The compliance with commitments failed in $84 \%$ of CTE controlled. In $65 \%$ the gap noticed between commitments and reality was major, in $12 \%$ it was significant, and in $23 \%$ it was low.

\section{Threshold effect and regulation for complete information situations}

In a complete information situation, the sites where environmental processes involve threshold effects are common knowledge. According to $\mathrm{Wu}$ (2004) recommendations, we assume that the regulator designs her scheme on a per-site basis and we focus on policy design for a given site. Last, we consider medium-term environmental effects.

Let us consider, as Dupraz et al. (2004), that the environmental effect, $K$, depends on the total area $S$ involved in the agri-environmental scheme and on the environmental effort $e$ that the farmers provide. The agro-environmental technology is denoted $K=g(S, e)$. 
As soon as the area cropped with agri-environmental practices is wide enough, and when the environmental effort on this area is important enough, the function $g($.$) is positive and$ increasing in $S$ and $e$. Moreover, we assume that $\delta g / \delta S \leq 0$ : we deliberately consider a concave environmental technology (Wirl, 1999) beyond the threshold. Last let us assume that $g_{S e}$, is negative: the marginal effect on the environment, with respect to the area, is decreasing on the environmental effort.

The threshold effect is formalised, with a simplification of usual characterisation of dynamic threshold effects (Lines, 2005), with the critical area $S_{0}$ and the critical effort $e_{0}$ below which no environmental effect is noticeable:

$$
\begin{aligned}
& S \leq S_{0}(e) \Rightarrow g(S, e)=0, \\
& e \leq e_{0}(S) \Rightarrow g(S, e)=0 .
\end{aligned}
$$

The farmer's reservation utility, when he is proposed to supply the effort $e$ on an area $s$, is formalised by his willingness to accept $c^{i}$. This willingness to accept differs from one farmer to the other and includes both the losses due to the adoption of the specific practices, which prevents the farmer to apply the production plan that corresponds to the higher profit for his farm, and the utility that the farmer directly derives, as a consumer, from the environmental effect $K$ :

$$
c^{i}=c^{i}(s, e, K) .
$$

This last assumption relies on several empirical studies regarding particular schemes and EU wide sample: evidence shows that farm households derive a direct satisfaction from their production of environmental services (Dupraz et al., 2002). On the other hand, if these empirical studies highlight a positive relationship between environmental practices adoption and the farmer's personal preferences for environment for some combinations of practices (like maintenance of landscape associated with biodiversity protection, or maintenance of landscape 
associated with water quality), these studies also point out that this relationship does not exist when the measures aim at non directly observable effects (for example protection of biodiversity, when the measure is not associated measures with locally evident effects). The specific behaviour of farmers who adopt costly practices because they value their environmental effect seems to be related to the production of tangible local public goods: the farmers have a special access to this local public good and thus their own effort if of importance for them.

The farmer's willingness to accept, $c^{i}(s, e, K)$, is increasing and convex in $s$ and $e$ but nonincreasing in $K$. The environmental effect is striven on an area large enough for one farmer not being able to provide alone this effect and the willingness to accept for the $i^{\text {th }}$ farmer depends on the number of farmers who adopt the measure in the area (Genicot et Ray, 2006).

Last, we assume that $c_{s K}$ the marginal willingness to accept (relative to the area) is decreasing in the environmental effect.

Let us denote $W(K)$ the regulator's willingness to pay for the environmental good $K$, reflecting the social surplus function. This function is classically increasing and concave in $K$. We normalise this function and assume that $W$ is null when $K=0$.

\subsection{Social optimum}

The social optimum is the solution of program (1) where $s_{i}$ is the area on which the $i^{\text {th }}$ farmer supplies the environmental effort $e$. The pair $\left(s_{i}, e\right)$ forms the environmental service supplied by the $i^{\text {th }}$ farmer.

$$
\max _{s^{i}, K, e}\left(W(K)-\sum_{i} c^{i}\left(s^{i}, e, K\right)\right)
$$




$$
\begin{array}{ll} 
& K=g\left(\sum_{i} s^{i}, e\right) \\
\text { s.c. } \quad & \forall i, \quad s^{i} \geq 0 \\
& \mathrm{e} \geq \mathrm{e}_{0}\left(\sum_{i} s^{i}\right) \\
& \sum_{i} s^{i} \geq S_{0}(e)
\end{array}
$$

As soon as one of the last two constraints is binding, the solution of this program is evident: all the variables and all the functions are null.

Beyond the threshold, the interior solution is characterised, using the envelop theorem, by the following equations:

$$
\begin{aligned}
& \sum_{i} c_{e}^{i}\left(s^{i}, e, K\right)=g_{e}\left(\sum_{i} s^{i}, e\right) \cdot\left(W^{\prime}(K)-\sum_{i} c_{k}^{i}\left(s^{i}, e, K\right)\right) \\
& s_{i}\left(c_{s}^{i}\left(s^{i}, e, K\right)-g_{s}\left(\sum_{i} s^{i}, e\right) \cdot\left(W^{\prime}(K)-\sum_{i} c_{k}^{i}\left(s^{i}, e, K\right)\right)\right)=0 ; \forall i=1, \ldots, n
\end{aligned}
$$

The first equation defines the optimal effort to which the areas $s^{i}$ are submitted. The $\mathrm{n}$ following equations determine the level of each of theses areas; the contracted areas for some farms can be null when the marginal cost for the first hectare exceeds the marginal benefit that the farmers realises when he applies the effort $e$ on this area. When $s^{i}$ is positive, its value is determined such that the marginal costs $\left(c_{s}^{i}\right)$ equals the marginal benefit $\left(g_{s \cdot}\left(W^{\prime}-\sum c_{k}\right)\right)$.

The social optimum cannot be reached without any regulation because the environmental effect $K$ cannot be realised under the action of one farmer only. If a farmer wishes to provide an environmental service, he can only anticipate $K=0$ and thus provides the effort $e$ on an area such that $\mathrm{c}_{s}^{i}\left(s^{i}, e, 0\right)=0$. Even if this farmer has a positive attitude towards the environment, economic considerations lead him not to provide the service on his own farm. 


\subsection{Agri-environmental regulation for complete information}

The regulator proposes to the farmers a standard contract, denoted $(e, p)$, that we will call agrienvironmental measure. This contract, as many standard contract used in EU agri-environmental policies, combines a per-hectare payment $p$ to the adoption by the farmer of agri-environmental practices on the contracted area. The agri-environmental practices result in an effort $e$ for the farmer. We assume here, because of complete information, that the effort can be observed without any additional cost.

In a complete information situation, the cost and utility functions for all the farmers, and the relationships between the effort (e), the proposed payment $(p)$ and the expected environmental effect $(K)$ are common knowledge.

The farmers who face the $(e, p)$ contract also faces uncertainties on the behaviour of the other farmers. They must anticipate this behaviour, with the information they have. Let us denote $K^{i}$ the anticipation that the $i^{\text {th }}$ farmers realises. This farmer maximises the expected benefit he can gain from contracting: $\max _{s}\left(p s-c\left(s, e K^{i}\right)\right)$. The solution of this maximisation is denoted $s^{i}(e$, $\left.p, K^{i}\right) ; s^{i}$ is positive or nul, non decreasing in $p$ et $K^{i}$ and non increasing in $e$. Formally, $s_{i}$ is such that :

$$
p=c_{s}^{i}\left(s^{i}\left(e, p, K^{i}\right), e, K^{i}\right)
$$

Differentiating this expression according to $K^{i}$, we obtain the following expression for the increase rate of the area:

$$
c_{s s}^{i}\left(s^{i}\left(e, p, K^{i}\right), e, K^{i}\right) \frac{\partial s^{i}}{\partial K^{i}}+c_{s K^{i}}\left(s^{i}\left(e, p, K^{i}\right), e, K^{i}\right)=0
$$

With our assumptions $\left(c_{s s}>0\right.$ and $\left.c_{s K}<0\right)$, a farmer who anticipates a better environmental effect contracts on a larger area. 
The regulator program consists in maximising a global welfare function, $U$, depending on the total contracted area $S$ only. Denoting $\lambda$ the marginal cost of public funds, this function can be expressed as:

$$
U(S)=W(K)-C(S)-\lambda p S
$$

$C(S)=\sum_{i=1}^{n} c^{i}\left(s^{i}, e, K^{i}\right)$ is the total willingness to accept of the farmers and the total contracted area is $S=\sum_{i=1}^{n} s^{i}\left(e, p, K^{i}\right)$.

The fonction $U(S)$ has a very specific form because of the threshold effect (Figure 1) :

- If $S<S_{0}(e), U(S)=-C()-\lambda p S$ is negative and decreasing, with a minimum for $S_{0}$.

- If $S \geq S_{0}(e), U(S)$ is concave, increasing on the right hand side of $S_{0}(e)$, but becomes eventually positive only after a second threshold $S_{m}(e, p)>S_{0}(e)$. Last, it is also possible that beyond a threshold $S_{M}(e, p) U$ becomes again negative (in this case, the area that the farmers propose for contracting is so large that the total costs involved by the scheme are far higher than the benefits of the measure.

\section{Figure 1}

If $U$ stays negative, it is optimal not to do anything and no contract is proposed to the farmers. In the other case, because the environmental technology is known and the adoption cost are common knowledge, the farmers correctly anticipate the consequences of the $(e, p)$ contract on the environmental effect, $K$. The $i^{t h}$ farmers proposes to contract on the area $s^{i}(e, p, K)$ such that:

$$
p=c_{s}^{i}\left(s^{i}, e, K\right)
$$

and the regulator's program becomes: 


$$
\begin{aligned}
& \max _{e, p, s^{i}, K} U \cong W(K)-\sum_{i} c^{i}\left(s^{i}, e, K\right)-\lambda p \sum_{i} s^{i} \\
& K=g\left(\sum_{i} s^{i}, e\right) \\
& \quad p=c_{s}^{i}\left(s^{i}, e, K\right) \\
& \text { with. } \quad \forall i, \quad s^{i} \geq 0 \\
& \quad \mathrm{e} \geq \mathrm{e}_{0}\left(\sum_{i} s^{i}\right) \\
& \sum_{i} s^{i} \geq S_{0}(e)
\end{aligned}
$$

The last two constraints are not binding because we consider situations beyond the threshold (below the threshold, it is optimal for the regulator to propose no contract at all). The first order conditions for this program provide the optimal contract $\left(e^{*}, p^{*}\right)$ that leads to a total contracted area $S^{*}=\sum s^{i}\left(e^{*}, p^{*}, K^{*}\right)$ :

$$
\begin{gathered}
(1+\lambda) p=g_{s}\left(\sum_{i} s^{i}, e^{*}\right) \cdot\left(W^{\prime}\left(K^{*}\right)-\sum_{i} c_{K}^{i}\left(s^{i}, e^{*}, K^{*}\right)\right) \\
\sum_{i} c_{e}^{i}\left(s^{i}, e^{*}, K^{*}\right)=g_{e}\left(\sum_{i} s^{i}, e^{*}\right) \cdot\left(W^{\prime}\left(K^{*}\right)-\sum_{i} c_{k}^{i}\left(s^{i}, e^{*}, K^{*}\right)\right)
\end{gathered}
$$

Equation (4) indicates that the payment provided per unit of contracted area, weighted by the total cost of public funds, equals the difference between the regulator's marginal willingness to pay (for a variation of $S^{*}$ ) and the farmers' marginal willingness to accept (for the same variation of $S^{*}$ ). Equation (5) determines the optimal amount of effort, which is the same as for the social optimum.

It is clear that the design of agri-environmental schemes is never performed in complete information situations. We shall examine how the contracts are modified when the farmers' 
private information is imperfectly known, first from the regulator only and second from both th regulators and the neighbouring farmers.

\section{Consequences of asymmetric information}

\subsection{Adoption cost unknown from the regulator only}

Let us assume, as a first stage, that the farmers on the regulated site have a common knowledge of their respective willingness to accept. In this case, they are able to correctly anticipate the environmental effect associated with any $(e, p)$ that is proposed to them. The asymmetry of information only occurs between the regulator and the farmers.

Of course, this asymmetry prevents the regulator from estimating the optimal effort $e^{*}$ that the farmers have to respect per unit of area, because its value depends, among other things, of the farmer's marginal willingness to accept $c_{e}$ and $c_{K}$. Now, the regulator has to fix arbitrarily an effort level $e$ (for example, she can rely on literature for comparable sites). This is the situation to which the local regulators dealing with the application of the second CAP pillar have been confronted. The regulator could still determine the associated payment $p$ while maximising a welfare function:

$$
\max _{p, s^{i}, K} U \cong W(K)-\sum_{i} c^{i}\left(s^{i}, e, K\right)-\lambda p \sum_{i} s^{i}
$$

subject to the same constraints as for the complete information case. Beyond the threshold, the first order conditions provide:

$$
(1+\lambda) p_{1}=g_{s}\left(\sum_{i} s^{i}, e\right) \cdot\left(W^{\prime}\left(K^{1}\right)-\sum_{i} c_{K}^{i}\left(s^{i}, e, K^{1}\right)\right)
$$

Even if she has no idea of the farmers' willingness to pay functions, the regulator has to rely on assumptions on the marginal utility that the farmers' derive from the environmental effect $K$ if she wants to be able to design a payment $\mathrm{p}_{1}$. 
The following step for the regulator consists in reducing wastes of public funds, i.e. avoids the situations where the payments induce no environmental effect or where $U$ is negative. In the first case, a simple solution for the regulator is to fix a threshold below which no contract is signed. The simpler level of this signal is $S_{0}(e)$ but this level does not warrant that the total welfare will be positive.

It is possible to avoid the situations where the welfare variation for the society is negative: the regulator can design a scheme that relies only on $W$ (and not on $C$, unknown from the regulator). The regulator can offer the higher possible payment that warrants a positive variation of welfare for the society (and that warrants that $W-p S \geq 0$ ): with $S_{E}$ being the maximal eligible area in the regulated site, the regulator can offer the payment $p_{E}=W\left(g\left(S_{E}, e\right)\right) / S_{E}$ that dries up the community willingness to pay if all the eligible area is contracted. The threshold that activates the contracting procedure (and that avoids situations with no environmental effect) is then defined by $p_{E}=W\left(g\left(S_{m}, e\right)\right) / S_{m}$. The concavity of $W$ implies $S_{m}(e)>S_{0}(e)$ (see Figure 2$)$.

\section{Figure 2}

Such a contract, denoted $\left(e, p_{E}, S_{m}\right)$, ensures that the social welfare variation is not negative. As the cost function $\mathrm{C}($.$) is uncertain for the regulator, the aggregated cost can be either over \left(C_{2}\right.$ on Figure 2) or below $W(S)\left(C_{l}\right.$ on Figure 2). But the design of $p_{E}$ and $S_{m}$, along with the growth of marginal costs ensure that contracts will be signed only when the total cost $C($.) is below $W($.) on the interval $\left[S_{m}, S_{E}\right]$. Otherwise, as the marginal cost is over $p_{E}$, the potentially contracting farmers who are necessary for getting over the threshold have a marginal cost greater than $p_{E}$ and are not willing to contract; as the threshold is not reached, the regulator does not validate any contract, which excludes the situations where the social welfare is negative $\left(U_{2}\right.$ on Figure 2). 
This kind of contract is not optimal because it excludes situations where the social welfare could be positive (note that $U_{l}$ is positive juste below $S_{m}$ ) and does not warrant that the contracted area maximises the social welfare because the payment does not depend on the farmers'willingness to accept.

The welfare function for a regulator proposing the $\left(e, p_{E}\right)$ contract is:

$$
U\left(p_{E}\right)=W\left(g\left(\sum_{i} s^{i}\left(p_{E}\right), e\right)\right)-\sum_{i} c^{i}\left(s^{i}\left(p_{E}\right), e, K_{2}\right)-\lambda p_{E} \sum_{i} s^{i}\left(p_{E}\right)
$$

Derivating this expression with respect to $s^{i}$ provides:

$$
\frac{\partial}{\partial s^{i}} U\left(p_{E}\right)=W^{\prime}\left(K_{2}\right) g_{s}\left(\sum_{i} s^{i}\left(p_{E}\right), e\right)-c_{s}^{i}\left(s^{i}\left(p_{E}\right), e, K_{2}\right)-\lambda p_{E}
$$

We can simplify the notations. Because we have $p_{E}=c_{s}$ ), this expression can be written: $\frac{\partial}{\partial s^{i}} U\left(p_{E}\right)=W^{\prime} g_{s}-(1+\lambda) p_{E}$. Now, with our assumptions we have $p_{E} \leq W^{\prime} g_{s}$. Thus, if the marginal cost of public funds is not too high, we also $\frac{\partial}{\partial s^{i}} U\left(p_{E}\right) \leq 0$ and we can deduct from this expression that $p_{E} \leq p_{1}$. In other words, when the regulator proposes a contract $\left(e, p_{E}, S_{m}\right)$ to the farmers, this contract leads to a sub-optimal area contracted.

\subsection{Individual willingness to accept unknown from both the regulator and the neighbouring farmers}

Let us examine now the case where the farmers do not know the way their neighbours are liable to act when facing a gri-environmental scheme. Facing a $(e, p)$ contract proposition, a farmer will individually anticipate the resulting environmental effect, $K^{i}$ and his own willingness to accept will be $c^{i}\left(s^{i}, e, K^{i}\right)$. It will be even more difficult for the regulator than on the previous 
case to calculate $e^{*}$. It will be nearly impossible to assess a payment for the supply of this effort, because for doing so, the regulator would need to know both the individual utilities that each farmers gains from the environmental effect and the way each farmer anticipates his neighbours reactions to the $(e, p)$ contract.

But the regulator still has the possibility to propose the contract $\left(e, p_{E}, S_{m}\right)$ described above. Moreover, announcing such a contract would act upon the $K^{i}$ anticipations of the farmers. Let us examine how. When facing a $\left(e, p_{E}, S_{m}\right)$ contract, the $i^{\text {th }}$ farmer can expect realising a benefit $\pi\left(s^{i}\left(e, p, K^{i}\right)\right)=p s^{i}\left(e, p, K^{i}\right)-c^{i}\left(s^{i}\left(e, p, K^{i}\right), e, K^{i}\right)$. This farmer will realise ex-post a profit (different from his expected benefit) denoted:

$$
\Pi\left(s^{i}\left(p, e, K^{i}\right), K\right)=p s^{i}\left(e, p, K^{i}\right)-c^{i}\left(s^{i}\left(e, p, K^{i}\right), e, K\right) .
$$

In the case where the farmer anticipates $K^{i}>K$, this farmer would have ex post a profit less high than the expected benefit (because $c_{K}$ is negative). On the contrary, when the environmental effect is greater than expected by the farmer $\left(K^{i}<K\right)$, this farmer realises ex post a profit greater than his expected benefit:

$$
\Pi\left(s^{i}\left(p, e, K^{i}\right), K^{i}\right)<\Pi\left(s^{i}\left(p, e, K^{i}\right), K\right)<\Pi\left(s^{i}(p, e, K), K\right) \quad \text { si } K^{i}<K(6)
$$

Proposing to the farmers a contrac $\mathrm{t}\left(e, p_{E}, S_{m}\right)$ comes down reducing the risk for these farmers to face ex post a situation where $K$ is null: if the total proposed area is below $S_{m}$, the regulator does not sign any contract. Thus, even when they ignore their neighbours' offers, it's the farmers' interest to anticipate $K^{i}$ at least equal to $g\left(S_{m}, e\right)$. When they want to optimise their individual offers $s^{i}$, it is even their interest to consult each other to correctly anticipate the final environmental effect (because their profit is greater when $K$ is positive). 
Such a contract $\left(e, p_{E}, S_{m}\right)$ is not optimal because $e$ is arbitrarily fixed by the regulator. Nevertheless, this mechanism allows distinguishing the sites where the implementation of agrienvironmental contracts is desirable from those where it is optimal to do nothing. This distinction is performed through the revelation of the collective environmental offer from the farmers in each site. The associated transaction cost is very low because the regulator only needs to send the signal $S_{m}$. Of course, this mechanism assumes that the regulator is able to determine her own willingness to pay, $W$.

\subsection{An example}

A first example found in Brittany can be presented. It is the implementation by the "Conseil général d'Ille et vilaine" (NUTS3 regional council) of particular contracts.

The regional authorities successively offered several contractual arrangement to favour the conversion of arable land in grassland buffer zone in areas along the river (Kerhouas, 2003).

The buffer zone aim at:

$>$ catching and filtering ground flow

$>$ slowing the streaming and avoiding soil erosion

$>$ filtering streaming water fixing the solved substances

avoiding river contamination which can occur after plant-care product spraying

Environmental impacts of buffer zones are well known. The installation of a buffer zone of $6 \mathrm{~m}$ leads to the catchment of nearly $70 \%$ of plant-care products streaming. For a buffer zone of $18 \mathrm{~m}, 90 \%$ of plant-care products are caught.

The budget allocated to this program reaches 760000 Euro for 2001-2006period. Three types of contracts exist. The first one deals with implementation of grasslands long the river for 375 Euro/ha if the implantation of buffer zone concern crops. The second one deals with 
implantation of buffer zones on temporary grassland for 259 Euro/ha. The last one is extensive management of grassland for 63,6 Euro/ha.

These amount are increased of $20 \%$ if the measures are adopted in a CTE "Contrat Territorial d'Exploitation"

The agreement concerns the installation of maintenance of grassland buffer zone of $20 \mathrm{~m}$ large. These agreements aims at protecting the rivers.

Their installation must be based on a precise diagnostic of the territorial conditions. Buffer zones have to be implemented on relevant positions on the watersheds.

This offer was contingent and would have been effective only if at least $60 \%$ of river bank of the targeted area was under contract. The eligible parcels were those described at $1 / 25000^{\text {th }}$ from IGN (Institut Géographique National).

To gather $60 \%$ of river bank of a targeted zone under contract was first an objective of the NUTS3 policy. This threshold of $60 \%$ was chosen according to an audit led on the previous 1994-1999 AES contracts aiming at creating grassland buffer zone. The conclusions of this audit showed that a minimum rate of $60 \%$ of conversion was needed to lead to efficient environmental impact on a catchment area. During 1994-1999, 536 contracts concerning 1,406 ha with creation of grassland buffer zones were signed. The total budget was 2900000 Euro and spent for nothing. The spatial dispersion of contracts signed did not permit any measured significant environmental impact. No consistent reasoning regarding catchment areas was initiated. It illustrates our situation S2.

After 1999, the "conseil général" contracts were proposed on a particular catchment area to test farmer reactions. After two years, the balance was disappointing because only 11 farmers had contracted and the parcels under contracts did not represent the $60 \%$ of the targeted area.

On the second chosen area, the threshold of $60 \%$ of the targeted area became not only an objective, but a necessary condition to engage contracts. Hence, this necessary condition aimed 
at reaching a minimal impact on environment and avoiding to give money without any results guarantee. Farmers, gathered around a project leader, signed a declaration of intent. They finally signed contracts once the area under contract reached the threshold. 34 contracts were signed on a particular watershed following an territorial approach. The chosen watershed was preferentially belonging to a "Contrat Eau paysage Environnement" (water landscape environment contract) signed with the "conseil général". The story of this particular example illustrates how the procedure using $\left(e, p, S_{m}\right)$ contracts initiate a cooperative behaviour of the farmers, at first to reach the threshold.

At a national level, the National Rural Development Program proposes measures to farmers in which threshold effects at the farm level are taken into account. For example, the sub-measure 8.1 "Introduction of integrated crop protection" is paid only if a precise part of the farm area is concerned by the decrease in the use of pesticides. The minimum part of the farm which has to be under contract is defined at the NUTS3 level to fit local conditions.

Scale effects are considered at the farm level in measures such as "Winter covering of arable land with intermediary culture". If the farm area committed in this measure reaches $40 \%$ of the farm area, then the paid amount is increased by $20 \%$ and if the area committed is less than $10 \%$ of the farm area, then the amount paid is decreased by $20 \%$.

The involvement of local and regional councils must be emphasised. Although scale and threshold effects are considered at the farm level by nationally designed measures, it seems that higher level threshold effects and the necessary coordination farmers' environmental efforts are only considered where local authorities are involved (Instance nationale d'évaluation du contrat territorial d'exploitation, 2003). In the few success stories which are reported they take advantage of successive experiences despite the deep changes that have affected the French 
agro-environmental policy framework. In contrast the schemes that are managed by the usual agricultural networks clearly privilege the access of all farmers to the wider range of contractual measures, without any knowledge accumulation strategy at the local level.

\section{Extensions}

\subsection{Moral hazard}

The other usual problem with information asymmetries is moral hazard, which occurs when the individual effort of each farmer, $e^{i}$ is difficult to observe and monitor. How surprising it looks, there are numerous examples of agri-environmental contracts with uncontrollable prescriptions (Instance Nationale d'Evaluation du Contrat Territorial d'Exploitation, 2003).

The classical second order solution is based on the risk aversion of the agents: the regulator performs costly controls on limited samples and applies very strong sanctions when the non compliance happens to be proved, in order to reduce the rate of non compliance (Holmström 1982). However the design of an appropriate control and sanction system is often limited by laws and pre-existing procedures that determine the maximum penalties in accordance with other references.

Once again a cooperative approach might be proposed if the effort $e^{i}$ of a particular farmer is easily observable by his/her neighbours. An example of such effort is the mowing of meadows from their centre to their periphery. This practice is recognised to be very efficient to preserve certain wildlife species. Although official controls are very difficult to organise, farmers frequently and easily and observe the way their neighbours perform. The basic idea is to design a contract between the regulator and a consortium of farmers of a designated area (see Segerson, 1988 mechanisme designed, which is based on Holmström, 1982, one). The consortium receive 
a global payment $\mathrm{P}=\mathrm{C}\left(\mathrm{p}^{*}, \mathrm{e}^{*}\right)$ for the provision of $\mathrm{K}^{*}$ and nothing if the environmental objective is not reached. Practically this means that the consortium has to reimburse the global payment, possibly with an additional penalty to cover administration cost and the opportunity cost of public funds. However the financial penalty per farmer would be much lower than the optimal sanction associated with individual contracts. As the consortium members are collectively committed and know each other, the enforcement of the contract makes use of social pressures based on personal relationships since few free riders endanger the payment of all the others.

\subsection{Uncertainty on agri-environmental technology}

The environmental technology is never totally unknown. In most cases, environmentalists have an idea of the underlying technology process and especially know if it exhibits threshold effects or doesn't. Under locally specific conditions, the exact threshold critical values are usually unknown. At least policy makers may use existing scientific references or similar experience to be aware of threshold effect and possibly get a hazy idea of these critical values. It must be emphasised that the farmer themselves often have less information about the agri-environmental processes than policy makers.

The challenge of the scheme design is to offer and monitor contracts that will produce additional information on the agri-environmental processes, and particularly the threshold critical values. An iterative process that includes successive contractual rounds is needed.

Without any hidden information by the farmers, standard contracts are first offered in few selected representative zones which are delimited according to the targeted environmental output and the suspected scale and threshold effects which are associated. If similar sites are available, different contracts $(e, p)$ may be tested in order to discover the critical values more rapidly and more precisely. Starting with rather high effort and payment, and providing a 
comfortable profit to farmers may provide advantages: the probability of the environmental good production being higher, the net social cost of the first contractual round will probably be lower, even if the social surplus does not reach the costs of the scheme. Moreover, a success will encourage the farmers for future contractual rounds while a failure might discourage them. Out of the monitoring of the scheme, the regulator will know ex-post if the thresholds have been reached or not. If it is relevant, an extra payment may be offered to associate the contractors to monitoring tasks. In the iterative process, where previous results are taken into account, the regulator can step by step reach the optimal contract and offer it in additional zones according to the recommendations of $\mathrm{Wu}$ (2004). A big difficult is the common case of the delayed response of the environmental efforts which slows down the production of knowledge.

Consultations between scientists, decision makers, farmers and environmental organisations should create a dynamic and trustful context where the targeted level of environmental impacts, the monitoring procedures and the contract are step by step redefined taking into account previous results. In such a context, interrelations between different measures described in literature regarding conservation programmes for instance $(\mathrm{Wu}, 2004)$ could also be analysed and taken into account in future design of contracts.

When the farmers' cost function are partly unknown by the regulator, setting a minimal aggregated area to trigger the State signature of $\left(e, p, S_{m}\right)$ contracts is no more useful in the context of uncertain threshold critical values. The ex post analysis of $(e, p)$ contracts will also provide the required information on the farmers' environmental supply function. Once again the elicitation of the farmers' willingness to accept under different scenarios may provide interesting complementary information. For instance the influence of the probability of the environmental production associated with different contracts may be tested, before such probability is eventually approximated. 
The moral hazard problem characterised by hidden efforts of the contractors is more difficult to deal with because the identification of the source of scheme failure is itself unknown. Still, the preceding proposal of a collective contract with a consortium of farmers may be preferred if the consortium is truly interested in the process of knowledge capitalisation about the agrienvironmental technology. Obviously, the farmers won't accept their payment is entirely conditioned by the observation of an environmental output that does not entirely depend on their efforts. Some kind of risk sharing system between the regulator and the consortium must be negotiated.

When remarkable biotopes are endangered by the trend of economic changes, Perrings and Pearce (1994) pointed out that the uncertainty about thresholds is often associated with the uncertainty and irreversibility of potential damages and of their social costs. They show that these cases resist conventional applied economics because no optimum is calculable. Therefore decision making about preservation must rely on non economic criteria. Hence the preservation of the status quo is enforced with strong penalties compared to the private profit of trespassing the conservative standards. Many agro-environmental schemes are used to preserve remarkable sites like marshes, peat land or mountainous dried meadows, from land abandonment or agricultural intensification. Using Perrings and Pearce results justify payments high enough to deter alternative use of land in the sites which are selected by policy makers. Sometimes such payments do not correspond to any tangible effort of the farmer.

\section{Conclusion}


The large variety of agri-environmental situation does not generally allow designing efficient schemes at a high territorial level. As observed by Mollard (2003), in France, the environmental effect has to be sought on regions small enough to allow tying consistency between actors and the resources they manage. Local communities appear to have a legitimate role to play in leading a progressive design of agri-environmental schemes that maintain motivation and cooperation between the different actors.

For a given region, an iterative process of knowledge capitalisation on small pertinent sites allows the iterative design of an optimised but standard contract that can be in a second step proposed on other comparable sites. The budget constraints the local communities have to bear will induce a competition between the different sites and an interaction with their own development plans. These plans can be considered at the regional level, given that the social willingness to pay for the community can be assessed per site. This paper highlights the importance to pinpoint the threshold effects that can occur in the environmental processes and suggests avenues to design more efficient policies.

When threshold effects occur, conditioning the payment to an intention of contracting $\left(S_{m}\right)$ greater than the area needed to pass the threshold $\left(S_{0}\right)$ lets the regulator to favour a cooperative solution, even when asymmetric information occurs on the farmers' willingness to accept. The scheme designed in this paper can be implemented in real case situations, as illustrated by the Ille-et-Vilaine example. Such a mechanism is not optimal but can be improved through a progressive design relying on the capitalisation of local knowledge.

In several empirical studies regarding particular schemes and EU wide examples, evidence shows that farm households derive a direct satisfaction from their production of environmental services (Dupraz, et al., 2002, 2003). This willingness to pay has to be considered by the regulator who wants to efficiently make use of public funds and ensure that the contracting 
process and the cooperation of actors can last along years. This willingness to pay can be mobilised through a better formation of farmers on agri-environmental processes and through the design of measures with credible expected environmental impacts.

The new dispositions regarding cross-compliance for European agricultural subsidies include commitment to reserve $3 \%$ of the area cropped with cereals, oilseeds and set-aside for grass strips. The areas involved are considerable and the potentially protected banks also: grass strips should reach 400,000 ha and 200 to $400,000 \mathrm{~km}$ of banks should be protected (Gril et al. 2004). In many cases, the farmers keep a leeway for the location of these grass strips. The conditions for implanting grass strips (including the different potential fixings and locations) should be adapted to each site, otherwise unacceptable constraints can be imposed to the farmers with no tangible environmental benefits occurring. A precise diagnosis of the whole area along with a capitalisation and a diffusion of the local knowledge acquired are thus essential for an optimal allocation of these new regulatory arrangements. 


\section{Acknowledgements}

This document presents results obtained within the EU project SSPE-CT-2003-502070 on Integrated tools to design and implemented Agro Environmental Schemes (http//:merlin.lusignan.inra.fr/ITAES). It does not necessary reflect the view of the European Union and in no way anticipates the commission's future policy in this area.

It also benefits from the financial support of French Ministry of Ecology and Sustainable Development: Project entitled "efficacité et acceptabilité des mesures agro-environnementales". 


\section{References :}

Arnaud S. (2004). Expression de la demande sociale pour les diverses fonctions de l'espace rural dans le Parc des Marais du Cotentin et du Bessin, Mémoire de DAA, INRA-ESR, Rennes, Faculté des sciences économique de Université de Montpellier 1, ENSA de Montpellier.

Asner G. P. et Vitousek P. M. (2005). Remote analysis of biological invasion and biogeochemical change." Proceedings Of The National Academy Of Sciences Of The United States Of America, 102 (12), 4383-4386.

Bonnieux F., Dupraz P., Retière C. (2001). Farmer's supply of environmental benefits » in Erling Vardal (Ed.) "Multifonctionality of Agriculture", Seminar Proceedings, February 1618, Department of Economics of the University of Bergen- Research Council of Norway, 105-133.

Bontems P., Rotillon G., et Turpin N. (2005). Self-selecting agri-environmental policies with an application to the Don watershed, Environemental and Resource Economics, 31, 275-301.

Dasgupta P., et Maler K.G. (2003). The Economics of Non-convex Ecosystems: Introduction, Environmental and Resource Economics, 26 (4), 499-525.

Dupraz P., Vanslembrouck I., Bonnieux F. et Van Huylenbroeck (2002). Farmers' participation in european agri-environmental policies, $X^{\text {th }}$ congress of the European Association of Agricultural Economists, Zaragoza (Spain), 28-31 août 2002, 14 pages.

Dupraz P., Vermersch D., Henry de Fraham B. et Delvaux L. (2003). The environmental supply of farm households : A flexible willingness to accept model, Environmental and Resource Economics, 25 (3)3, 171-189. 
Dupraz P. et Rainelli P. (2004). Institutional approaches to sustain rural landscapes in France, in Brouwer F.(ed.) "Sustaining Agriculture and the Rural Economy", Edward Elgar Publishing, 162-182.

Dupraz P., Latouche K. et Bonnieux F. (2004). Economic implication of scale and threshold effects in agri-environmental processes, in Proceedings of 90th EAAE Seminar: Multifunctional agriculture, policies and markets: understanding the critical linkage, Rennes, October 28-29, 2004).

Eureval C3E (2003). Evaluation à mi-parcours portant sur l'application en France du règlement C.E ${ }^{\circ}{ }^{1257-1999}$ du Conseil, concernant le soutien au développement rural, partie sur le soutien à l'agro-environnement (chapitre VI du R.D.R.) et le contrat territorial d'exploitation en Basse-Normandie, Rapport final MAE, 15 juin 2003, 164 pages.

Falconer K., Dupraz P. et Whitby M. (2001). An Investigation of Policy Administrative Costs Using Panel Data for the English Environmentally Sensitive Areas, Journal of Agricultural Economics, 52 (1), 83-103.

Finn, J.A.; Bourke, D.; Kurz, I. and Dunne, L. (2007). Estimating the environmental performance of agri-environmental schemes via use of expert consultations: ITAES WP5 Final report. 133p.

Genicot G. et Ray D. (2006). Contracts and externalities: How things fall apart. Journal of Economic Theory, 131(1), 71-100.

Gril J.J. et Lacas J.G. (2004). Intérêt des zones tampons enherbées et boisées pour limiter le transfert diffus des produits phytosanitaires vers les milieux aquatiques. De l'état des connaissances aux recommandations pratiques. Rapport d'étude, 37pages

Holmström B. (1982). Moral Hazard in Teams, Bell Journal of Economics, 13(2), 324-340.

Instance Nationale d'Evaluation du Contrat Territorial d'Exploitation (2003). Le programme CTE, Rapport d'évaluation. Décembre 2003, 177 pages.

ITCF et Agences de l'eau (1998). Etude de l'efficacité des dispositifs enherbés, 30 Pages, Septembre 
Kennedy T. A., Naeem S., Howe K. M., Knops J. M. H., Tilman D., et Reich P. (2002). Biodiversity as a barrier to ecological invasion, Nature, 417(6889), 636-638.

Kerhouas Y. (2003). La mise en œuvre de mesures Agro-environnementales sur le département d’Ille et Vilaine. Dispositif "Bandes Enherbées, rapport du conseil général d’Ille et Vilaine. $70 \mathrm{p}$.

Laffont J.-J. et Martimort D. (2002). The Theory of Incentives: The Principal-Agent Model, Princeton University Press, 360 p.

Lancelot F. (2001). Le renouveau des bandes enherbées le long des rivières, La Terre, semaine du 28 Février au 6 Mars 2001.

Levin S. A. (1998). Resilience in Natural and Socioeconomic Systems, Environment and Development Economics, 3(2), 222-234.

Lines M. (2005). Intertemporal Equilibrium Dynamics with a Pollution Externality, Journal of Economic Behavior and Organization, 56(3), 349-364.

Maler K.G. (2000). Development, Ecological Resources and Their Management: A Study of Complex Dynamic Systems, European Economic Review, 44(4-6), 645-665.

Mitra T., et Roy, S. (2006). Optimal exploitation of renewable resources under uncertainty and the extinction of species, Economic Theory, 28, 1-23.

Mollard A. (2003). Multifonctionnalité de l'agriculture et territoires : des concepts aux politiques publiques. Cahiers d'économie et sociologie rurales, 66, 28-54.

Morris C. et Potter, C. (1995). Recruiting the new conservationists: farmers' adoption of agrienvironment schemes in the UK, Journal of Rural Studies 11: 51-63.

Muradian R. (2001). Ecological thresholds: a survey, Ecological Economics, 38 (1),7-24.

OCDE (2003). Voluntary Approaches for Environmental Policy - Effectiveness, Efficiency and Usage in Policy Mixes, Paris.

Parkhurst G.M., Shogren J., Bastian C., Kivi P., Donner J., smith R. B.W. (2002), Agglomeration bonus: an incentive mechanism to runite fragmented habitat for biodiversity conservation, Ecological Economics, 41, 305-328. 
Pascal Consultants - CNASEA (2003). Evaluation des MAE et CTE à mi-parcours en Bretagne. Rapport final provisoire, Juin 2003, 75 pages.

Perrings C. et Pearce D. (1994). Threshold effects and Incentives for the Conservation of Biodiversity, Environmental and Resource Economics 4, 13-28.

Ribaudo M.O. (2004). Policy Explorations and Implications for Nonpoint Source Pollution Control: Discussion. American Journal of Agricultural Economics 86(5), 1220-1221

Rondeau D. (2001). Along the Way Back from the Brink, Journal of Environmental Economics and Management, 42(2), 156-182.

Segerson K. (1988). Uncertainty and incentives for nonpoint pollution control, Journal of Environmental Economics and Management, 15, 87-98.

Toman M. A., et Withagen C. (2000). Accumulative Pollution, "Clean Technology," and Policy Design, Resource and Energy Economics, 22(4), 367-384.

Vanslembrouck I., Van Huylenbroeck G., et Verbeke W. (2002). Determinants of the willingness of Belgian farmers to participate in Agri-environmental measures, Journal of Agricultural Economics, 53 (3), 489-511.

Weersink A et al. (1998). Economic Instruments and Environmental Policy in Agriculture. Canadian Public Policy, 24(3), 309-327.

Weisner S. E. B., Strand J. A., et Sandsten H. (1997). Mechanisms regulating abundance of submerged vegetation in shallow eutrophic lakes, Oecologia, 109(4), 592 - 599.

Wirl F. (1999). Complex, Dynamic Environmental Policies, Resource and Energy Economics, 21(1), 19-41.

Wirl F. (2004). Thresholds in Concave Renewable Resource Models, Ecological Economics, 48(2), 259-267.

Wu J. (2004). Using Sciences to improve the economic efficiency of conservation policies, Agricultural and Resource Economics Review, 33(1), 18-23. 
Wu J. et Babcock BA (1996). Contract design for the purchase of environmental goods from agriculture, American Journal of Agricultural Economics, 78, 935-945. 


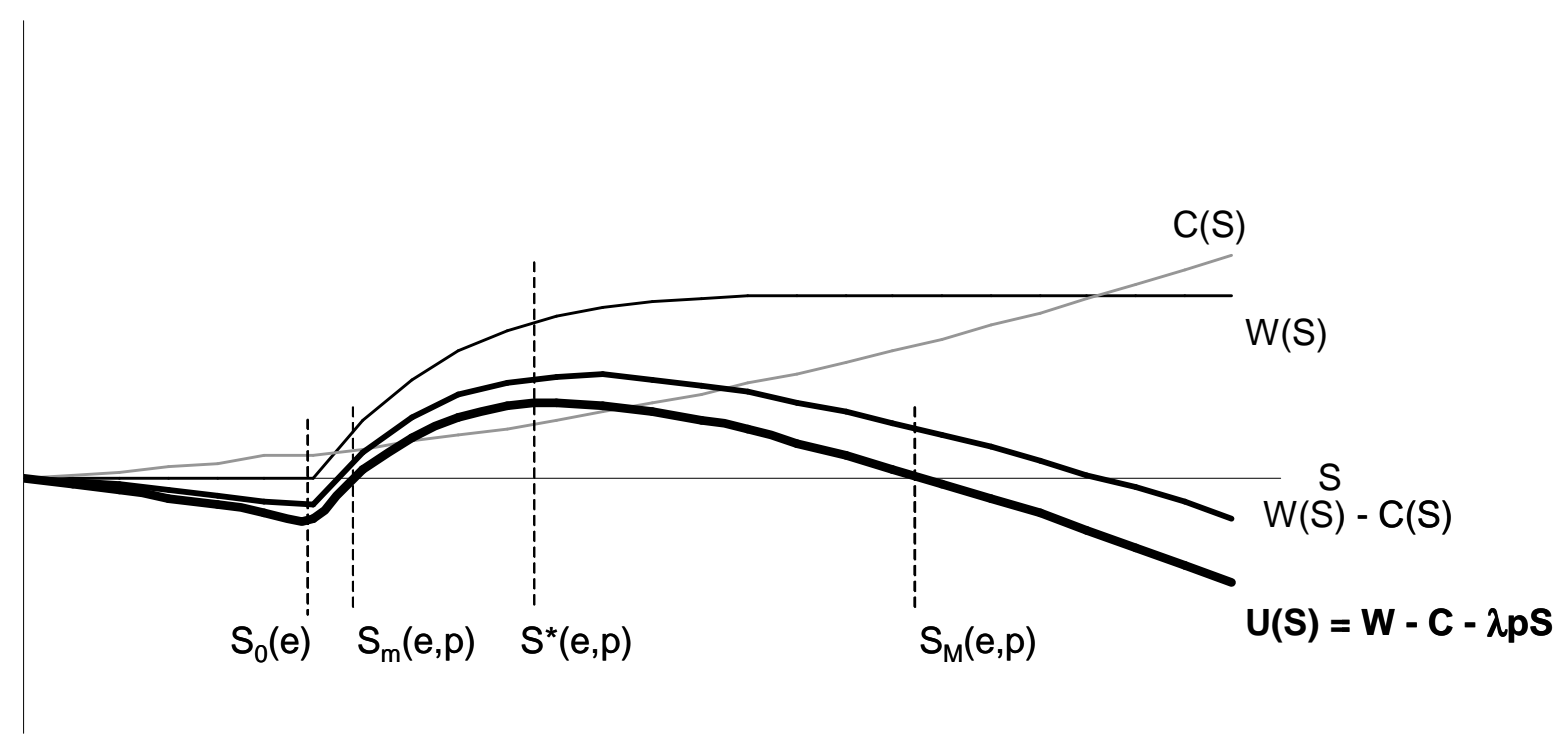

Figure 1 regulator willingness to pay (W), adoption cost for the farmers $(C)$ and social welfare (U) for a given effort (e), in a complete information situation where the environmental technology is known 


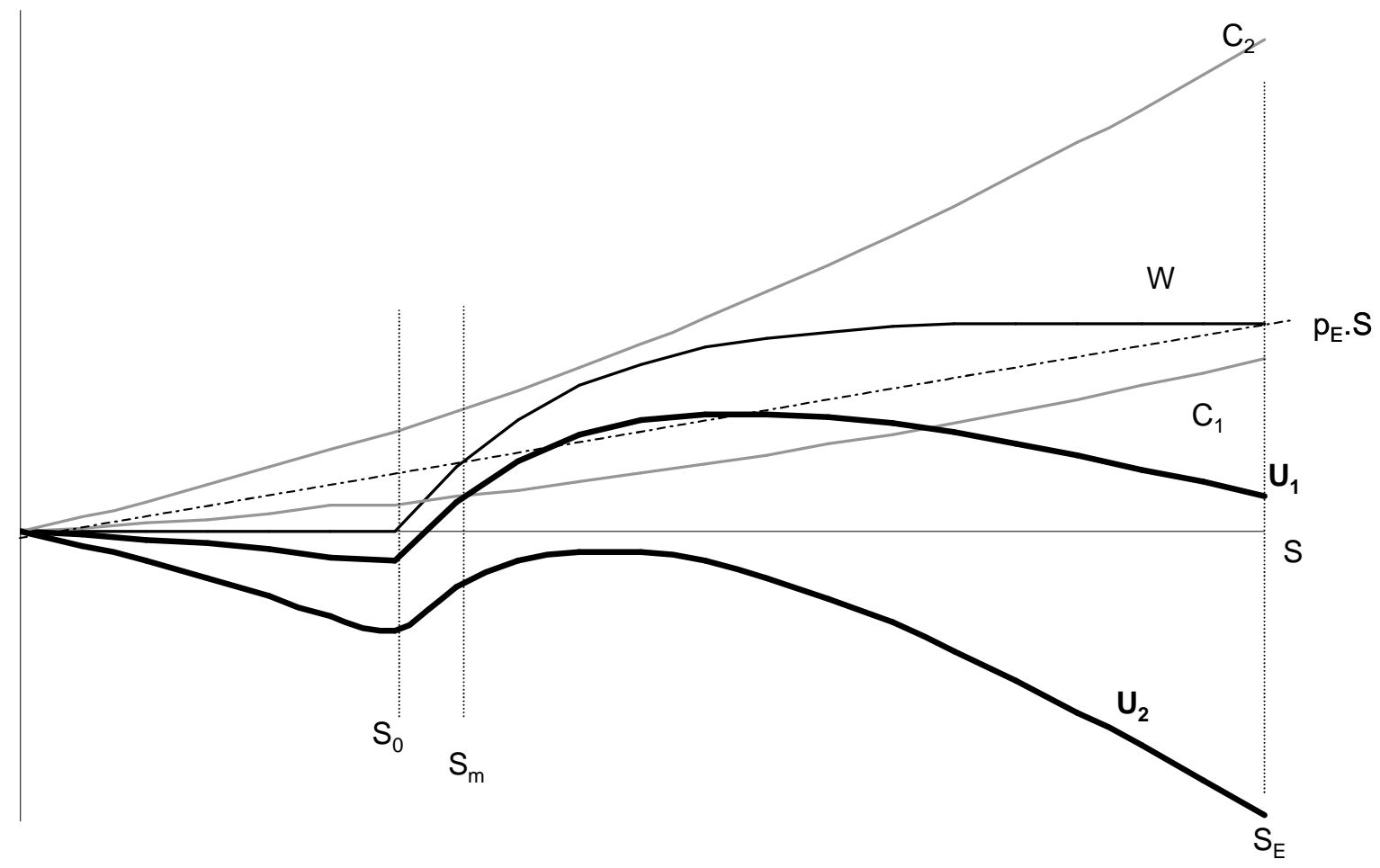

Figure 2 : regulator's utility, adoption cost and social welfare, depending on the total contracted area 